\title{
Letter from the Editors-in-Chief
}

This issue includes articles that delve into topics such as squirrels dealing with living in human disturbed areas; fitness routines of volleyball players; the production and use of "trench newspapers" by soldiers in the First World War; and new feminist approaches to pornography. Part of the beauty of producing a multidisciplinary journal is the range of themes available to explore upon virtually opening this book.

To say we are pleased to present this second issue of the University of Saskatchewan Undergraduate Research Journal is an understatement.

We could not be more proud of our contributors, editors, and community in making this second issue not only possible, but also a contribution to our general body of knowledge. We believe in the merits of undergraduate research. We value the original ideas of students who demonstrate that impassioned work and unique perspectives are the hallmarks of great human knowledge-not academic credentials. Across this issue and last year's inaugural launch, our authors and USURJ volunteers showed that students are capable of the same level of professional research as their professors and administrators. Given support, access, and publication platforms typically restricted to post-graduate and professional researchers, our undergraduates continue to show that excellence is first and foremost a matter of accessibility and desire.

At USURJ we believe in open-source technologies, public access to research, and creating educational opportunities for students. Student submissions go through the same blind, multiple peer-review process seen in other academically credited journals. Following the review stage, submissions pass through a series of revisions managed by various editorial teams. Authors are then asked to edit and rework any revisions deemed necessary to ensure the highest quality and legitimacy of publication. Once published, their works are connected to the same, larger academic databases used by researchers worldwide (such as Google Scholar, EBSCO, and so on). Because we follow the procedures and regulations typical to most credible academic journals, when a student submits their work they have the opportunity to learn how to publish, placing a series of experiences in the hands of our undergrads in such a way that they are given the tools that are necessary in their later academic career.

In closing, we continue to encourage any and all of you doing undergraduate research within any discipline to submit your work. Encourage those around you who you feel have great ideas, a strong style, a needed voice, or an important message, to contribute to USURJ.

Thank you for reading.

Nicole Haldoupis \& Cale Passmore

Editors-in-Chief 